\title{
There's that: unifying existential and list readings
}

\section{Jutta M. Hartmann}

\section{Introduction ${ }^{1}$}

Syntactic research dealing with the there-construction in English mostly puts aside the list reading exemplified in (1) as a separate reading not relevant for the questions investigated.

(1) A: Did we call everyone?

B: No, there is still John and Mary.

Yet, there are some notable exceptions as e.g. Belletti (1988) and Safir (1985). I will argue here (along with Safir 1985) that if we look at the there-construction as a copula construction, it is possible to unify the existential and list reading. However, as will become clear in the final section, both Belletti's (1988) and Safir's (1985) analyses are not entirely adequate, because not every definite DP that occurs in the thereconstruction gives rise to the list reading.

In order to understand the proposal, we have to look into the research concerning copula sentences, which has established that we have to distinguish (at least) two types of predication occurring with the copula. Consider the examples in (2).

(2) a. Peter is ill.

b. Mary's husband is Peter.

The first type is the 'real', predicative type as seen in (2a). Here, the predicate 'ill' is applied to 'John', thus, expressing that 'John' belongs to the set of individuals who are ill. I will refer to this type of reading as predicational. The second type in (2b) is different. Instead of predicating 'Peter' over 'Mary's husband', it rather specifies 'Peter' as the one who is 'Mary's husband'. I will refer to this type of predication as specificational. Putting aside the discussions about the correct analysis of these two types

\footnotetext{
1 This research is made possible by the Netherlands Organisation of Scientific Research (NWO), grant 276-70-001, which is hereby gratefully acknowledged.
} 
of copula constructions, ${ }^{2}$ I will argue here, that we find the same two types with the there-construction: the existential reading is an instance of a predicational copula sentence and the list reading is on a par with the specificational reading.

\section{Types of Predication in Copula Sentences}

The literature on classifying the types of predication in copula constructions is rich both in content as well as in terminology, resulting in a somewhat confusing picture of what is relevant for a classification. Without trying to review the literature and terms used, I will partly follow Huber (2002) who suggests categories of copula structures by cross-classifying sets vs. individuals as subjects vs. predicates. For this paper and possibly in general, the relevant semantic distinction seems to be the element in predicative position. Thus, I will stick to a two-fold distinction between what I call predicational and specificational copula clauses. In this way, we arrive at the classification of examples in (3) to (6) as given in table 1 (the various terms circling the literature added):

(3) Peter is ill

(4) Whales are mammals.

(5) The evening star is the morning star.

(6) What I don't like about Peter is his tie.

${ }^{2}$ The main discussions in the literature centre around the question of whether the ambiguity arises from a lexical ambiguity of the copula 'be' or from a structural difference. On the side of the structural ambiguity camp, an influential analysis has been the one where the specificational predication is seen as an inverted structure of the predicational. (cf. among others Moro 1997). More recent analyses have argued against this view. (cf. among others Heycock and Kroch 1998, Rothstein 2001) assigning the ambiguities to a difference in the small clause structure that the copula embeds. (cf. especially Adger and Ramchand for a proposal along this line). Another line of research is additionally occupied with the question of whether two types are enough, or whether we need to have an additional structure for identity clauses like The morning star is the evening star. 
Table 1: Classification of Predication (along the lines of Huber 2000)

\begin{tabular}{|c|c|c|c|}
\hline $\begin{array}{l}\text { Subject } \\
\text { Position }\end{array}$ & $\begin{array}{l}\text { Predicate } \\
\text { Position }\end{array}$ & $\begin{array}{l}\text { Terms used } \\
\text { here }\end{array}$ & Terms in the literature \\
\hline Individual & Set & \multirow{2}{*}{$\begin{array}{l}\text { predicational } \\
\text { cf. (2), (3) }\end{array}$} & $\begin{array}{c}\text { predicative, predicational, } \\
\text { identificational }\end{array}$ \\
\hline Set & Set & & Generic \\
\hline Individual & Individual & \multirow{2}{*}{$\begin{array}{l}\text { specificational } \\
\text { cf. (4), (5) }\end{array}$} & identity, equative \\
\hline Set & Individual & & specificational, equative \\
\hline
\end{tabular}

The main argument for keeping the two classes of specification vs. predication apart comes from coordination data: It is possible to coordinate two sets or two individuals in predicate position, but not individuals with sets (cf. Huber 2002):

(7) a. Whales are mammals and highly intelligent.

b. Venus is the morning star and the evening star.

c. ${ }^{*}$ The woman in the corner is a fool and Mary.

What complicates the issue is that whether a predicate is a set or an individual in the semantic sense does not cut along syntactic categories: DPs and CPs (mainly wh-clefts) can be both individuals and sets (of properties) creating ambiguities between two readings that sometimes cannot be kept apart easily. Generally, DPs can be proper names, definite DPs or indefinite DPs. ${ }^{3}$ Proper names (as e.g. 'John') are in most cases referential expressions, thus fall under the class of individuals. In contrast to these, indefinite DPs (e.g. 'a fool') express a set in the default case, but not in all cases: they can also have a specific reading in which they are interpreted as referring to individuals. Definite DPs have a strong tendency to refer to individuals, but still, they can also be interpreted as denoting a set of properties: thus, 'the teacher' can be used to refer to a specific person, but it can also express a (singleton) set of the property of being a teacher. ${ }^{4}$ Thus, there is a mismatch between the syntactic category and the semantic distinction between sets (properties) and individuals. One result of

\footnotetext{
${ }^{3}$ Bare nouns of the type in Mary is president of the committee are also possible. I put them aside, as they might be NPs or DPs and their interpretation as predicates is not disputed.

${ }^{4}$ Here, my approach differs significantly from Safir (1985), who assumes that definite DPs cannot be predicates in general (Safir 1985:118).
} 
this mismatch is that especially when we have a structure of the form $D P$ be $D P$ we deal either with a predicational or a specificational structure. Consider (8):

Mary is the chief editor of the TIME magazine.

(8) can mean that there is a person, 'Mary', and another person, 'the chief editor of the TIME magazine', and what we state is that they refer to the same individual. In this sense, we are dealing with a specificational reading of the copula construction in my classification (or in other terms, the identity, equative reading). Additionally, there is a different reading available as well: 'Mary' has the property of being the chief editor of the TIME magazine, a property that is a singleton set. If we invert the clause, the second, predicational reading is not (readily) available and it is hard to imagine a reading in which 'Mary' is a set of properties that are relevant here: ${ }^{5}$

The chief editor of the TIME magazine is Mary.

Putting aside these important issues, the main point that I want to make is that it matters whether the predicate position is filled with a phrase expressing a set or an individual (skipping over the possibly complicating fact of the nature of the subject of predication). Taking this step, we expect copula constructions to cluster in two pairs: predicational and specificational sentences. On the assumption that the verb be in theresentences is the copula (and not an auxiliary), ${ }^{6}$ the prediction is that we should find both readings here as well. The main claim of this paper is that when the post-copular position is filled with a DP denoting a set (the predicational reading), the existential meaning arises. Whenever the postcopular position is filled with a DP referring to an individual (the specificational reading), we end up with the list reading. ${ }^{7}$

\footnotetext{
${ }^{5}$ A possible interpretation of this type could be the 'role reading': The chief editor of the TIME magazine is Hamlet expresses something like 'The chief editor of the TIME magazine has the property of being Hamlet', a paraphrase which suggests the 'role' reading that the sentence has, cf. Doron (1988:295).

${ }^{6}$ There in English also occurs with unaccusative verbs in restricted contexts. I exclude these here as they seem to be different from the existential construction in important respects, cf. Hartmann (2005).

${ }^{7}$ In doing this, I want to remain neutral about the question what difference it makes that there occupies the subject position in contrast to general copula constructions
} 


\section{The existential reading: an instance of a predicational structure}

The main arguments to treat the existential as a predicational structure come from parallelism arguments by McNally (1992) as summarised by Zamparelli (2000). First of all, both DPs in predicational structures as well as existential constructions cannot take wide scope:

(10)a. There weren't two people drunk.

$\mathrm{Neg}>2, * 2>\mathrm{Neg}$

b. John and Mary aren't two students I know.

$\mathrm{Neg}>2, * 2>\mathrm{Neg}$

Secondly, McNally shows that in both constructions, strong quantifiers can only occur if they range over kinds:

(11)a. There was every kind of wine available for tasting.

b. "? There was every worker ready.

(12)a. John has been every kind of doctor.

b. *John has been every doctor.

Thirdly, for both types of predicates, it is not possible (for most speakers) to relativise a predicate nominal with a $w h$-relative pronoun. ${ }^{8}$

(13)a. The people * who / that / Ø there were at the party were drunk.

b. They dressed like the eccentric women ${ }^{*}$ who / that / $\varnothing$ they were.

Furthermore, Zamparelli (2000) argues that we can grasp the similar semantics if we understand the meaning of the existential as the postcopular property being asserted over a location meaning "that that space 'is' or 'contains' [e.g.] a man. The only case in which this assertion is ever going to be true is when a man is in existence." (Zamparelli 2000:188).

On the syntactic side, Williams (1994) argues that the DP patterns with predicates with respect to $w h$-extraction. The contrast of (14) versus (15)

in which the subject is another DP. Another possibility that I do not want to exclude a priori is that we might have to distinguish between the predicative heads that lead to general copula constructions and the predicative heads that derive existentials.

${ }^{8}$ There is only one problem with the postcopular DP in the there-construction: contrary to garden variety predicate nominals, pronouns can refer back to it: There is a god and he sometimes says no. (cf. Doron 1988 for this test). For a possible solution, see McNally (1992:62f). 
shows that predicates tend to be less extractable from $w h$-islands than arguments (the examples are adjusted from Williams (1994)):

(14)a. "What do you wonder who fixed?

b. 'Who do you wonder why Bill likes?

(15) a. *How tall do you wonder who became?

b. *How foolish do you wonder why Bill considers anyone $t$ ?

The postverbal-DP of the there-construction patterns with predicative DPs as seen in (16). Thus, Williams argues, it must be a predicate as well.

(16) a. *Who do you wonder why there was at the party?

b. *How many people do you wonder why there were?

\section{The list reading: an instance of specificational predication}

So far, we have seen that the existential reading clusters with predicational copula clauses. The next step to take is to show that list readings pattern with the specificational predication. There are two arguments in favor of this move. First of all, Higgins $\left(1973: 213^{9}\right)$ pointed out with respect to pseudocleft constructions that specification opens a list of which the postcopular DP is a (unique) member (see also Safir 1985). Thus, in (17), the specificational pseudocleft opens the list of items ("those things that I do not like about John') and then, we state that the list contains the item in post-copular position, 'John's tie'.

(17) What I don't like about John is his tie.

A similar reading is induced by specificational copula constructions. Here again, the precopular DP opens the list, here 'Angie's friends', and then, we give the items for this list, the relevant individuals.

$$
\text { Angie's friends are Peter, Paul and Catherine (among others). }
$$

With there-sentences matters are slightly different: the preverbal constituent is there and as such is not able to open a list. However, as soon as the list is salient in the context, there can pick up this list and the postcopular DP fills it in.

\footnotetext{
${ }^{9}$ Page numbers refer to the 1979 Garland publication of Higgins' dissertation.
} 
(19) A: Whom shall we invite to our party?

B: Well, there's John, Mary and David.

Secondly, it is not possible to coordinate the two types of predications in the there-sentences, just as much as we have seen it for copula structures in general.

(20) a. "Gabi's husband is Peter but not a lucky person.

b. " There's a god and John. ${ }^{10}$

\section{On definite DPs in there-constructions}

So far, we have seen that it makes sense to analyse the there-construction in the frame of copula clauses. Now the question is whether my way of looking at there-sentences improves on approaches already present. The testing ground are definite DPs occurring with the construction (in limited circumstances). On my account, we would expect that definites occur in the construction under two circumstances: either these definites are interpreted as sets giving the existential reading, or they are interpreted as individuals in which case they need a salient list in the context. On Safir's (1985) and also on Belletti's (1988) analysis definite DPs should give rise to a list reading. In essence, Safir argues that whenever a definite DP occurs in the structure, it needs case and the specificational copula (but not the predicational copula) can assign case. Therefore, the two have to co-occur, predicting that every definite DP has to instantiate the list reading. Belletti (1988) even more closely links definites with the list reading. She argues that a DP that receives partitive case is interpreted as an item of the list. ${ }^{11}$ However, none of these predictions are true. In particular, with respect to my account, not every definite DP that can occur as a predicate can occur in the there-construction, as we see in (21). ${ }^{12}$

${ }^{10}$ Example (20b) is not as awkward as example (20a). This effect is due to the availability of the list reading with 'a. (specific) god' and 'John' on the list.

"For both approaches this is essential as they otherwise lose their account for the definiteness restriction. Due to the limited space, I cannot further elaborate on their approaches, and the reader is referred to the originals for the in depth analyses.

${ }^{12}$ Sentence $(21 \mathrm{~b})$ of course is acceptable if we have a deictic there or if we read the sentence in a list context. However, under the existential reading this sentence is not possible. 
(21) a. John is the president of the committee.

b. "There is the president of the committee.

Thus, in my analysis, I still have to take into account some formulation of the definiteness restriction for the existential reading (possibly along the lines of McNally 1992). However, contra Safir's (1985) and Belletti's (1988) prediction, there are also definites occurring with there that cannot easily be subsumed under the list reading. In order to show this, I will discuss the data given in the seminal work by Birner \& Ward (1998).

First of all, I think we can exclude the so-called false definites as seen in the examples in (22) and (23). In these examples, a definite occurs, but the definite article can be replaced by an indefinite article without a change in the truth conditions of the sentences, thus, we are not dealing with real definites and I put these examples aside.

(22) What can happen is a hangup such as Rocky Smith ran into, as the independent hauler was traversing Chicago with a load of machinery that just had to get to a factory by morning. "There was this truck in front of me carrying giant steel coils, and potholes all over the place," he remembers, "This guy swerves all of a sudden to avoid a big hole." He hit it anyway.

(23) One day last year on a cold, clear, crisp afternoon, there was this huge sheet of ice in the street.

The second class of definites that occur with there are the ones discussed already: 'list readings'. Thus in (24), the salient list is the list of the two components in Division $\mathrm{H}$; in (25), it is the list of possible birthday presents.

And there's two components in [Division H], which is the operations division: the people that do the flight activity planning procedures work, $[\ldots]$ And then, there is the payload support folk, who provide for customer operations integration and support [...]

(25) A: What could I give my sister for her birthday

B: There's John's book on birdwatching.

In contrast to Birner and Ward (1998), however, I think, more of their examples can be grouped under the list reading context. Thus, in (26) and 
(27), the beginning of the sentence with 'in addition' suggests, that a list is salient in the context:

(26) In addition to interest-rate risk, there is the added risk that when interest rates fall, mortgages will be prepaid, thereby reducing the Portfolio's future income stream.

(27) In addition, as the review continues, there is always the chance that we'll uncover something additional that is significant.

Furthermore, to my eye, sentences that Birner and Ward group under the reminder context, can be treated as list reading as well. The salient list is exactly the list of things to remember:

(28) Caspian's hand had gone to his sword hilt, when Lucy said, "And you've almost promised Ramandu's daughter to go back." Caspian paused. "Well, yes. There's that," he said. He stood irresolute for a moment and then shouted out to the ship in general.

(29) A: I cannot imagine what I'm going to make for dinner tonight.

B: Well, there's that leftover meatloaf.

Nevertheless, it is not possible to subsume all definites occurring in the there-construction under the list reading. First of all, there is the group of sentences in which the existence of the definite DP is asserted. Clearly, these definites do not fall under the specificational reading but under the existential (predicational) reading of the there-construction. ${ }^{13}$

(30) But there is not any evidence, but there was this 10 thousandths.

(31) I think there was one flight where we had one problem. It wasn't ours, but there was that one flight. Other than that, I believe the answer to the remaining flight is yes.

Furthermore, there is a group of examples from two of Birner and Ward's classes. (the hearer-new tokens of hearer-old types, cf. (32), and hearernew entities with individuating descriptions, cf. (33)) that are not easily subsumed under the list reading. All of these examples can be uttered out of

\footnotetext{
${ }^{13}$ This type of example seems to occur typically with stress on the copula, which is another sign of the strong assertion of existence they need.
} 
the blue, suggesting that they need not rely on a salient list in the context. An interesting and possibly important fact about these examples is that they occur with a PP.

(32) a. There was the usual crowd at the beach today.

b. There were the same people at both conferences.

(33) a. There was that deaf comedienne I was telling you about on TV today.

b. There was the stupidest article on the reading list.

There is something strange about the definites in (32): the definite article seems to be required internally. Also, one might argue that the examples in (33) need not be considered under a definite restriction, because they have a flavour of expressing an opinion about the postverbal DP. But even if we can exclude (32) and (33) we are still left with the examples in (30), which to my eye are neither easily put aside nor can be subsumed under the list reading. Finally, an informal search in the British National Corpus provides further examples where a list reading seems not to be available:

Almost every nation in central and Latin America, Africa and South East Asia seems to be suffering from environmental decline, and although the basis of quantification might be questioned, at least there is the framework of a sub-regional, quantified data base on environmental decline. (BNC, text: APN, 38)

(35) There isn't the accommodation to cram in those extra people! (BNC, text: AMD, 593).

As my approach allows for definites occurring with the existential reading, this suggests that my approach is on the right track, although I have to leave the question of an appropriate definition of the definiteness effect to further research.

\section{References}

Adger, David, and Gillian Ramchand. 2003. Predication and Equation. Linguistic Inquiry 34: 325-359.

Belletti, Adriana. 1988. The Case of Unaccusatives. Linguistic Inquiry 19:1-34.

Birner, Betty, and Gregory Ward. 1998. Information Status and Noncanonical Word Order in English. Amsterdam/ Philadelphia: John Benjamins. 
Doron, Edit. 1988. The Semantics of Predicate Nominals. Linguistics 26: 281-303. Enç, Müvet. 1991. The Semantics of Specificity. Linguistic Inquiry 22: 1-25.

Hartmann, Jutta M. 2005. Why there is(n't) $w$-movement in there-constructions. In Linguistics in the Netherlands, ed. by Jenny Doetjes and Jeroen van de Weijer, 87-98. Amsterdam: Benjamins.

Heycock, Caroline, and Anthony Kroch. 1998. Equation and Inversion in Copula Clauses. In Papers in Linguistics 10,71-87. Berlin: ZAS.

Higgins, Francis R. 1973. The Pseudocleft Construction in English. PhD thesis, MIT. [Published by Garland in 1979].

Huber, Stefan. 2002. Es-Clefts and Det-Clefts. Zur Syntax, Semantik und Informationsstruktur von Spaltsätzen im Deutschen und Schwedischen. $\mathrm{PhD}$ Dissertation, University of Lund.

Keenan, Edward L. 1987. A Semantic Definition of 'Indefinite NP'. In The Representation of. (In) definiteness, ed. by Eric Reuland and Alice ter Meulen, Alice, 286-317. Cambridge, MA: MIT Press.

McNally, Louise. 1992. An Interpretation for the English Existential Construction. Ph.D.thesis, University of California, Santa Cruz.

Moro, Andrea. 1997. The Raising of Predicates: Predicative Noun Phrases and the Theory of Clause Structure. Cambridge/ New York: CUP.

Rothstein, Susan. 2001. Subjects and Predicates. Dordrecht: Kluwer.

Safir, Kenneth. 1985. Syntactic Chains. Cambridge/ New York: CUP.

Williams, Edwin. 1994. Thematic Structure in Syntax. Cambridge, MA.: MIT Press.

Zamparelli, Roberto. 2000. Layers in the Determiner Phrase. New York/London: Garland. 